\title{
M/M/1 Bulk Arrival and Bulk Service Queue with Randomly Varying Environment
}

\author{
Rama Ganesan ${ }^{1}$, Ramshankar.R ${ }^{2}$, Ramanarayanan. $\mathrm{R}^{3}$ \\ ${ }^{1}$ Independent Researcher B.Tech, Vellore Institute of Technology, Vellore, India \\ ${ }^{2}$ Independent Researcher MS9ECO, University of Massachusetts,Amherst, MA, USA \\ ${ }^{3}$ Professor of Mathematics, (Retired),Dr.RR \& Dr.SR Technical University, Chennai.
}

\begin{abstract}
This paper studies two stochastic bulk arrival and bulk service queueing Models $(A)$ and $(B)$ with $k$ varying environments. The system has infinite storing capacity and the arrival and service sizes are finite valued random variables. Matrix partitioning method is used to study the models. In Model (A) the maximum of the arrival sizes in all environments is greater than the maximum of the service sizes in all environments and the infinitesimal generator is partitioned as blocks of $k$ times the maximum of the arrival sizes for analysis and in Model (B) the maximum of the arrival sizes in all environments is less than the maximum of the service sizes in all environments where the generator is partitioned using blocks of $k$ times the maximum of the service sizes. The basic system generator is seen as a block circulant matrix. The stationary queue length probabilities, its expected values, its variances and probabilities of empty levels are derived for the two models using the rate matrix iterated. Numerical examples are presented for illustration. Bulk arrival and bulk service M/PH/I and PH/M/1 queues become special cases of the models when the PH generator is identified as the generator of the randomly varying environment.
\end{abstract}

Keywords: Block Circulant Matrix, Bulk Arrival, Bulk Service, Matrix Geometric Methods, Phase Type Distribution.

\section{Introduction}

In this paper two bulk arrival and bulk service queues have been studied with random environment using matrix geometric methods. Aissani.A and Artalejo.J.R [1] and Ayyappan, Subramanian and Gopal Sekar [2] have analyzed retrial queueing system using matrix geometric methods. Bini, Latouche and Meini [3] have studied numerical methods for Markov chains. Chakravarthy and Neuts [4] have discussed in depth a multiserver queueing model. Gaver, Jacobs and Latouche [5] have treated birth and death models with random environment. Latouche and Ramaswami [6] have studied Analytic methods. For matrix geometric methods and models one may refer Neuts [7]. The models considered in this paper are general compared to existing queueing theory models. Here random number of arrivals and random number of services are considered at a time whereas a fixed number of customers arrive and are served at any arrival or service epochs in many queueing models. Bulk service queueing model with service for fixed $\mathrm{b}$ customers when more than $\mathrm{b}$ customers are waiting has been studied by Neuts and Nadarajan [8]. In the models considered, the service sizes are of random size. In a similar way arrival sizes of customers are usually fixed in bulk arrival queueing systems but the models here treat bulk arrival of customers subject to a probability law. In real life situations when a machine manufactures a fixed number of products in every production schedule, the defective items are rejected in all production lots, making the production lot is only of random size and not a fixed one always. Further in the models considered here, the arrival rates, the service rates, the probabilities of bulk sizes of arrivals and service, change whenever changes occur in the randomly varying environments. Such situations are seen often in software based industries where finished software projects waiting for marketing are sold in bulk sizes when there is economic boom and the business may be very dull when there is economic recession. In industrial productions, bulk types are very common. Manufactured products arrive in bulk sizes and several bulk sizes of products are sold in markets. In general demands vary depending on market requirements. Recently M/M/1 queueing systems with disaster has been studied by Noam Paz and Uri Yechali [9]but random arrival size or random service size with varying environments have not been treated at any depth. Usually bulk arrival models have M/G/1 upper-Heisenberg block matrix structure with zeros below the first sub diagonal. The decomposition of a Toeplitz sub matrix of the infinitesimal generator is required to find the stationary probability vector. Matrix geometric structures have not been noted so far as mentioned by William J. Stewart [10]. But in this paper the partitioning of the matrix is carried out in a way that the stationary probability vector exhibits a matrix geometric structure for finite bulk queues with randomly varying environment.

Two models (A) and (B) on M/M/1 bulk queueing systems under $k$ varying environments with infinite storage space for customers are studied here using the block partitioning method to obtain matrix geometric results. In the models considered here, the maximum arrival sizes and the maximum service sizes are different 
for different environments. Model (A) presents the case when $\mathrm{M}$, the maximum of all the maximum arrival sizes in all the environments is bigger than $\mathrm{N}$, the maximum of all the maximum sales sizes in all the environments. In Model (B), its dual, $\mathrm{N}$ is bigger than $\mathrm{M}$, is treated. In general in Queueing models, the state space of the system has the first co-ordinate indicating the number of customers in the system but here the customers in the system are grouped and considered as members of $\mathrm{M}$ sized blocks of customers (when $\mathrm{M}>\mathrm{N}$ ) or $\mathrm{N}$ sized blocks of customers (when $\mathrm{N}>\mathrm{M}$ ) for finding the rate matrix. Using the maximum of the bulk arrival size or maximum of the bulk service size and grouping the customers as members of the blocks for the partitioning the matrices of the infinitesimal generator is a new approach in this area. The matrices appearing as the basic system generators in these two models due to block partitions are seen as block circulant matrices. The stationary probability of the number of customers waiting for service, the expectation, the variance and the probability of empty queue are derived for these models. Numerical cases are presented to illustrate their applications. M/PH/1 and PH/M/1 bulk arrival and bulk service queues become special cases of $\mathrm{M} / \mathrm{M} / 1$ bulk queues with randomly varying environments treated here when the $\mathrm{PH}$ generator is identified as the generator of the randomly varying environment.

The paper is organized in the following manner. In section II and section III the M/M/1 bulk arrival and bulk service queues with randomly varying environment in which maximum arrival size $M$ is greater than maximum service size $\mathrm{N}$ and the maximum arrival size is $\mathrm{M}$ less than the maximum service size $\mathrm{N}$ are studied respectively. In section IV, bulk arrival and bulk service M/PH/1 and PH/PH/1 queues are treated as special cases. In section V numerical cases are presented and section VI presents the conclusion.

\section{Model (A). Maximum Arrival Size M is Greater Than the Maximum Service Size N}

\subsection{Assumptions for $M>N$.}

i)There are k environments. The environment changes as per changes in a continuous time Markov chain with infinitesimal generator $\mathcal{Q}_{1}$ of order k.

ii) Customers arrive in different bulk sizes for service. The time between consecutive bulk arrivals of customers has exponential distribution with parameter $\lambda_{\mathrm{i}}$, in the environment $\mathrm{i}$ for $1 \leq \mathrm{i} \leq \mathrm{k}$. At each bulk arrival in the environment $i, \chi_{i}$ customers arrive with probability given by $P\left(\chi_{i}=j\right)=p_{j}^{i}$ for $1 \leq j \leq M_{i}$ and $\sum_{j=1}^{M_{i}} p_{j}^{i}=1$ for $1 \leq i \leq k$ iii) Customers are served in different bulk sizes. The time between consecutive bulk services of customers has exponential distribution with parameter $\mu_{\mathrm{i}}$ in the environment $\mathrm{i}$ for $1 \leq \mathrm{i} \leq \mathrm{k}$. At each service epoch in the environment $i, \psi_{i}$ customers are served with probability given by $P\left(\psi_{i}=j\right)=q_{j}^{i}$ for $1 \leq j \leq N_{i}$ when more than $N_{i}$ customersare waiting for service where $\sum_{j=1}^{N_{i}} q_{j}^{i}=1$. When $n$ customers $n<N_{i}$ are waiting for service, then $j$ customers are served with probability, $q_{j}^{i}$ for $1 \leq j \leq n-1$ and $n$ customers are served with probability $\sum_{j=n}^{N_{i}} q_{j}^{i}$ for $1 \leq$ $\mathrm{i} \leq \mathrm{k}$.

iv) When the environment changes from i to $\mathrm{j}$, the parameters of times between consecutive bulk arrivals and consecutive bulk services change from $\left(\lambda_{i}, \mu_{i}\right)$ to $\left(\lambda_{j}, \mu_{j}\right)$, the bulk arrival size $\chi_{i}$ changes to $\chi_{j}$, the bulk service size $\psi_{\mathrm{i}}$ changes to $\psi_{\mathrm{j}}$ and the maximum arrival size $\mathrm{M}_{\mathrm{i}}$ and the maximum service size $\mathrm{N}_{\mathrm{i}}$ change to $\mathrm{M}_{\mathrm{j}}$ and $\mathrm{N}_{\mathrm{j}}$ respectively for $1 \leq \mathrm{i}, \mathrm{j} \leq \mathrm{k}$.

v) The maximum of the maximum of arrival sizes $M=\max _{1 \leq i \leq k} M_{i}$ is greater than the maximum of the maximum of service sizes $\mathrm{N}=\max _{1 \leq \mathrm{i} \leq \mathrm{k}} \mathrm{N}_{\mathrm{i}}$.

\subsection{Analysis}

The state of the system of the continuous time Markov chain $\mathrm{X}(\mathrm{t})$ under consideration is presented as follows.

$X(t)=\{(n, j, i):$ for $0 \leq j \leq M-1 ; 1 \leq \mathrm{i} \leq \mathrm{k}$ and $\mathrm{n} \geq 0\}$

The chain is in the state $(n, j, i)$ when the number of customers in the queue is $n M+j$, for $0 \leq \mathrm{j} \leq \mathrm{M}-1$ and $0 \leq \mathrm{n}<$ $\infty$ and the environment is $\mathrm{i}$ for $1 \leq \mathrm{i} \leq \mathrm{k}$. When the number of customers in the system is $\mathrm{r}$, then $\mathrm{r}$ is identified with $(n, j)$ where $r$ on division by $M$ gives $n$ as the quotient and $j$ as the remainder. Let the survivor probability of the number of arrivals be

$\mathrm{P}\left(\chi_{\mathrm{i}}>\mathrm{j}\right)=\mathrm{P}_{\mathrm{j}}^{\mathrm{i}}=1-\sum_{\mathrm{n}=1}^{\mathrm{j}} \mathrm{p}_{\mathrm{n}}^{\mathrm{i}}$, and $\mathrm{P}_{0}^{\mathrm{i}}=1$ for $1 \leq \mathrm{j} \leq \mathrm{M}_{\mathrm{i}}-1$, in the environment $\mathrm{i}$ for $1 \leq \mathrm{i} \leq \mathrm{k} \cdot(2)$ Let the survivor probability of number of services be

$P\left(\psi_{i}>j\right)=Q_{j}^{i}=1-\sum_{n=1}^{j} q_{n}^{i}$, and $Q_{0}^{i}=1$ for $1 \leq j \leq N_{i}-1$ in the environment $i$ for $1 \leq \mathrm{i} \leq \mathrm{k}$

The chain $X(t)$ describing model has the infinitesimal generator $Q_{A}$ of infinite order which can be presented in block partitioned form given below. 
$\mathrm{Q}_{\mathrm{A}}=\left[\begin{array}{cccccccc}\mathrm{B}_{1} & \mathrm{~A}_{0} & 0 & 0 & . & . & . & \cdots \\ \mathrm{A}_{2} & \mathrm{~A}_{1} & \mathrm{~A}_{0} & 0 & . & . & . & \cdots \\ 0 & \mathrm{~A}_{2} & \mathrm{~A}_{1} & \mathrm{~A}_{0} & 0 & . & . & \cdots \\ 0 & 0 & \mathrm{~A}_{2} & \mathrm{~A}_{1} & \mathrm{~A}_{0} & 0 & . & \cdots \\ 0 & 0 & 0 & \mathrm{~A}_{2} & \mathrm{~A}_{1} & \mathrm{~A}_{0} & 0 & \cdots \\ \vdots & \vdots & \vdots & \vdots & \ddots & \ddots & \ddots & \ddots\end{array}\right]$

In (4) the states of the matrices are listed lexicographically as $\underline{0}, \underline{1}, \underline{2}, \underline{3}, \ldots . \underline{\mathrm{n}}, \ldots$. Here the vector $\underline{\mathrm{n}}$ is of type $1 \mathrm{x}$ $\mathrm{k} \mathrm{M}$ and $\underline{\mathrm{n}}=((\mathrm{n}, 0,1),(\mathrm{n}, 0,2) \ldots \quad(\mathrm{n}, 0, \mathrm{k}),(\mathrm{n}, 1,1),(\mathrm{n}, 1,2), \ldots(\mathrm{n}, 1, \mathrm{k}), \ldots(\mathrm{n}, \mathrm{M}-1,1),(\mathrm{n}, \mathrm{M}-1,2) \ldots(\mathrm{n}, \mathrm{M}-1, \mathrm{k})$ for $\mathrm{n} \geq 0$.

The matrices $B_{1}$ and $A_{1}$ have negative diagonal elements, they are of order Mk and their off diagonal elements are non- negative. The matrices $\mathrm{A}_{0}$, and $\mathrm{A}_{2}$ have nonnegative elements and are of order $\mathrm{Mk}$ and they are given below. Let the following be diagonal matrices of order $\mathrm{k}$

$\Lambda_{j}=\quad \operatorname{diag}\left(\lambda_{1} p_{j}^{1}, \lambda_{2} p_{j}^{2}, \ldots, \lambda_{k} p_{j}^{k}\right) \quad$ for $1 \leq j \leq M ; U_{j}=\operatorname{diag}\left(\mu_{1} q_{j}^{1}, \mu_{2} q_{j}^{2}, \ldots, \mu_{k} q_{j}^{k}\right)$ for $1 \leq j \leq N(5)$

$V_{j}=\operatorname{diag}\left(\mu_{1} Q_{j}^{1}, \mu_{2} Q_{j}^{2}, \ldots, \mu_{k} Q_{j}^{k}\right)$ for $1 \leq j \leq N ; \Lambda=\operatorname{diag}\left(\lambda_{1}, \lambda_{2}, \ldots, \lambda_{k}\right) ; U=\operatorname{diag}\left(\mu_{1}, \mu_{2}, \ldots, \mu_{k}\right)$ (6)

Let $Q_{1}^{\prime}=Q_{1}-\Lambda-\mathrm{U}$.

Here $Q_{1}$ is the infinitesimal generator of the Markov chain of the environment.

$\mathrm{A}_{0}=\left[\begin{array}{cccccc}\Lambda_{\mathrm{M}} & 0 & \cdots & 0 & 0 & 0 \\ \Lambda_{\mathrm{M}-1} & \Lambda_{\mathrm{M}} & \cdots & 0 & 0 & 0 \\ \Lambda_{\mathrm{M}-2} & \Lambda_{\mathrm{M}-1} & \cdots & 0 & 0 & 0 \\ \Lambda_{\mathrm{M}-3} & \Lambda_{\mathrm{M}-2} & \ddots & 0 & 0 & 0 \\ \vdots & \vdots & \ddots & \ddots & \vdots & \vdots \\ \Lambda_{3} & \Lambda_{4} & \cdots & \Lambda_{\mathrm{M}} & 0 & 0 \\ \Lambda_{2} & \Lambda_{3} & \cdots & \Lambda_{\mathrm{M}-1} & \Lambda_{\mathrm{M}} & 0 \\ \Lambda_{1} & \Lambda_{2} & \cdots & \Lambda_{\mathrm{M}-2} & \Lambda_{\mathrm{M}-1} & \Lambda_{\mathrm{M}}\end{array}\right](8)$

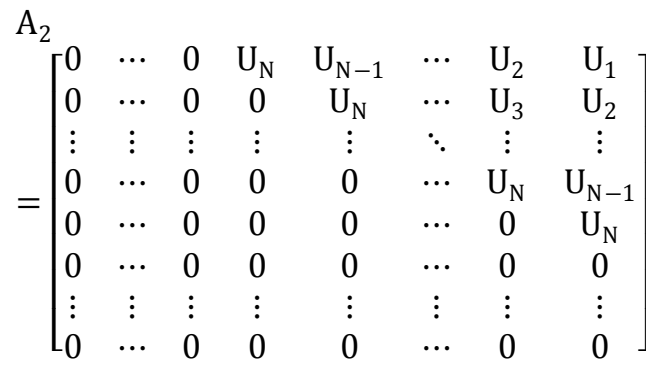

$$
\begin{aligned}
& \mathrm{A}_{1}=\left[\begin{array}{cccccccccc}
\mathcal{Q}_{1}^{\prime} & \Lambda_{1} & \Lambda_{2} & \cdots & \Lambda_{\mathrm{M}-\mathrm{N}-2} & \Lambda_{\mathrm{M}-\mathrm{N}-1} & \Lambda_{\mathrm{M}-\mathrm{N}} & \cdots & \Lambda_{\mathrm{M}-2} & \Lambda_{\mathrm{M}-1} \\
\mathrm{U}_{1} & Q_{1}^{\prime} & \Lambda_{1} & \cdots & \Lambda_{\mathrm{M}-\mathrm{N}-3} & \Lambda_{\mathrm{M}-\mathrm{N}-2} & \Lambda_{\mathrm{M}-\mathrm{N}-1} & \cdots & \Lambda_{\mathrm{M}-3} & \Lambda_{\mathrm{M}-2} \\
\mathrm{U}_{2} & \mu \mathrm{U}_{1} & Q_{1}^{\prime} & \cdots & \Lambda_{\mathrm{M}-\mathrm{N}-4} & \Lambda_{\mathrm{M}-\mathrm{N}-3} & \Lambda_{\mathrm{M}-\mathrm{N}-2} & \cdots & \Lambda_{\mathrm{M}-4} & \Lambda_{\mathrm{M}-3} \\
\vdots & \vdots & \vdots & \ddots & \vdots & \vdots & \vdots & \ddots & \vdots & \vdots \\
\mathrm{U}_{\mathrm{N}} & \mathrm{U}_{\mathrm{N}-1} & \mathrm{U}_{\mathrm{N}-2} & \cdots & \mathcal{Q}_{1}^{\prime} & \Lambda_{1} & \Lambda_{2} & \cdots & \Lambda_{\mathrm{M}-\mathrm{N}-2} & \Lambda_{\mathrm{M}-\mathrm{N}-1} \\
0 & \mathrm{U}_{\mathrm{N}} & \mathrm{U}_{\mathrm{N}-1} & \cdots & \mathrm{U}_{1} & Q_{1}^{\prime} & \Lambda_{1} & \cdots & \Lambda_{\mathrm{M}-\mathrm{N}-3} & \Lambda_{\mathrm{M}-\mathrm{N}-2} \\
0 & 0 & \mathrm{U}_{\mathrm{N}} & \cdots & \mathrm{U}_{2} & \mathrm{U}_{1} & Q_{1}^{\prime} & \cdots & \Lambda_{\mathrm{M}-\mathrm{N}-4} & \Lambda_{\mathrm{M}-\mathrm{N}-3} \\
\vdots & \vdots & \vdots & \ddots & \vdots & \vdots & \vdots & \ddots & \vdots & \vdots \\
0 & 0 & 0 & \cdots & \mathrm{U}_{\mathrm{N}} & \mathrm{U}_{\mathrm{N}-1} & \mathrm{U}_{\mathrm{N}-2} & \cdots & Q_{1}^{\prime} & \Lambda_{1} \\
0 & 0 & 0 & \cdots & 0 & \mathrm{U}_{\mathrm{N}} & \mathrm{U}_{\mathrm{N}-1} & \cdots & \mathrm{U}_{1} & \mathcal{Q}_{1}^{\prime}
\end{array}\right] . \\
& \mathrm{B}_{1}=\left[\begin{array}{cccccccccc}
Q_{1}-\Lambda & \Lambda_{1} & \Lambda_{2} & \cdots & \Lambda_{\mathrm{M}-\mathrm{N}-2} & \Lambda_{\mathrm{M}-\mathrm{N}-1} & \Lambda_{\mathrm{M}-\mathrm{N}} & \cdots & \Lambda_{\mathrm{M}-2} & \Lambda_{\mathrm{M}-1} \\
\mathrm{U} & Q_{1}^{\prime} & \Lambda_{1} & \cdots & \Lambda_{\mathrm{M}-\mathrm{N}-3} & \Lambda_{\mathrm{M}-\mathrm{N}-2} & \Lambda_{\mathrm{M}-\mathrm{N}-1} & \cdots & \Lambda_{\mathrm{M}-3} & \Lambda_{\mathrm{M}-2} \\
\mathrm{~V}_{1} & \mathrm{U}_{1} & Q_{1}^{\prime} & \cdots & \Lambda_{\mathrm{M}-\mathrm{N}-4} & \Lambda_{\mathrm{M}-\mathrm{N}-3} & \Lambda_{\mathrm{M}-\mathrm{N}-2} & \cdots & \Lambda_{\mathrm{M}-4} & \Lambda_{\mathrm{M}-3} \\
\vdots & \vdots & \vdots & \ddots & \vdots & \vdots & \vdots & \ddots & \vdots & \vdots \\
\mathrm{V}_{\mathrm{N}-1} & \mathrm{U}_{\mathrm{N}-1} & \mathrm{U}_{\mathrm{N}-2} & \cdots & Q_{1}^{\prime} & \Lambda_{1} & \Lambda_{2} & \cdots & \Lambda_{\mathrm{M}-\mathrm{N}-2} & \Lambda_{\mathrm{M}-\mathrm{N}-1} \\
0 & \mathrm{U}_{\mathrm{N}} & \mathrm{U}_{\mathrm{N}-1} & \cdots & \mathrm{U}_{1} & Q_{1}^{\prime} & \Lambda_{1} & \cdots & \Lambda_{\mathrm{M}-\mathrm{N}-3} & \Lambda_{\mathrm{M}-\mathrm{N}-2} \\
0 & 0 & \mathrm{U}_{\mathrm{N}} & \cdots & \mathrm{U}_{2} & \mathrm{U}_{1} & Q_{1}^{\prime} & \cdots & \Lambda_{\mathrm{M}-\mathrm{N}-4} & \Lambda_{\mathrm{M}-\mathrm{N}-3} \\
\vdots & \vdots & \vdots & \ddots & \vdots & \vdots & \vdots & \ddots & \vdots & \vdots \\
0 & 0 & 0 & \cdots & \mathrm{U}_{\mathrm{N}} & \mathrm{U}_{\mathrm{N}-1} & \mathrm{U}_{\mathrm{N}-2} & \cdots & \mathcal{Q}_{1}^{\prime} & \Lambda_{1} \\
0 & 0 & 0 & \cdots & 0 & \mathrm{U}_{\mathrm{N}} & \mathrm{U}_{\mathrm{N}-1} & \cdots & \mathrm{U}_{1} & Q_{1}^{\prime}
\end{array}\right]
\end{aligned}
$$

$Q_{\mathrm{A}}^{\prime \prime}=$ 


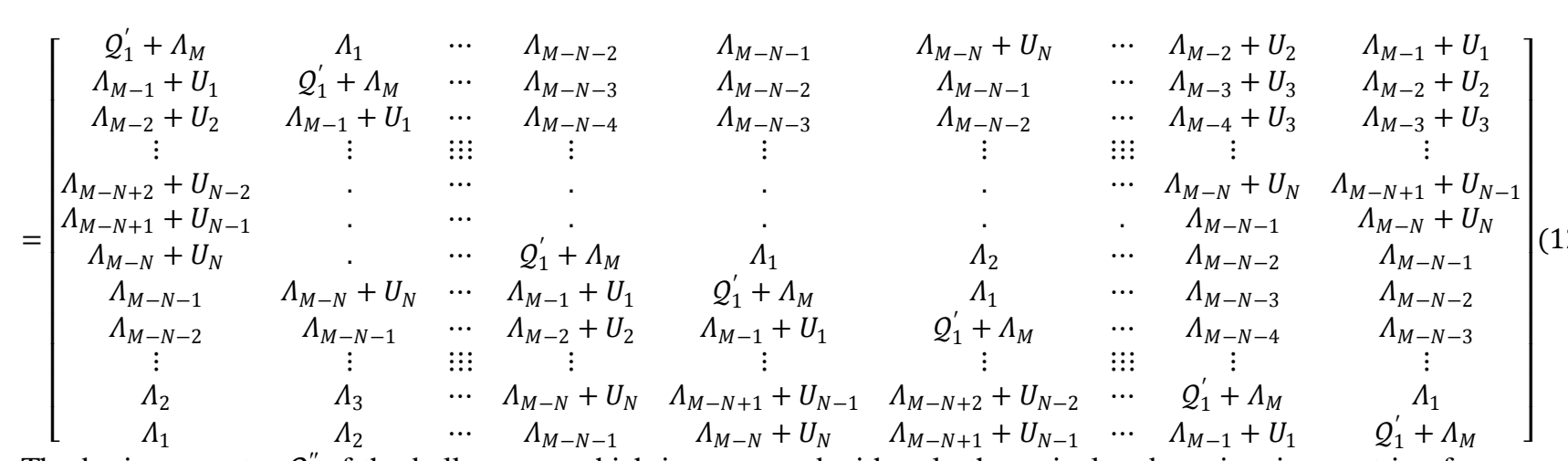

The basic generator $\mathcal{Q}_{\mathrm{A}}^{\prime \prime}$ of the bulk queue, which is concerned with only the arrival and service, is a matrix of order Mk given above in (12) where $Q_{\mathrm{A}}^{\prime \prime}=\mathrm{A}_{0}+\mathrm{A}_{1}+\mathrm{A}_{2}$ Its probability vector $\mathrm{w}$ gives, $\mathrm{w} \mathcal{Q}_{\mathrm{A}}^{\prime \prime}=0$ and $\mathrm{w}$. $\mathrm{e}=1$

It is well known that a square matrix in which each row (after the first) has the elements of the previous row shifted cyclically one place right, is called a circulant matrix. It is very interesting to note that the matrix $\mathcal{Q}_{\mathrm{A}}^{\prime \prime}$ $=A_{0}+A_{1}+A_{2}$ is a block circulant matrix where each block matrix is rotated one block to the right relative to the preceding block partition. Let the probability vector of the environment generator $\mathcal{Q}$ be $\pi$. Then $\pi \mathcal{Q}=0$ and $\pi \mathrm{e}=1$. It can be seen in (13) that the first block-row of type $\mathrm{k} x \mathrm{Mk}$ is,

$\mathrm{W}=\left(Q_{1}^{\prime}+\Lambda_{\mathrm{M}}, \Lambda_{1}, \Lambda_{2}, \ldots \Lambda_{\mathrm{M}-\mathrm{N}-2}, \Lambda_{\mathrm{M}-\mathrm{N}-1}, \Lambda_{\mathrm{M}-\mathrm{N}}+\mathrm{U}_{\mathrm{N}}, \ldots \Lambda_{\mathrm{M}-2}+\mathrm{U}_{2}, \Lambda_{\mathrm{M}-1}+\mathrm{U}_{1}\right)$

This gives as the sum of the blocks $\left(Q_{1}^{\prime}+\Lambda_{\mathrm{M}}\right)+\Lambda_{1}+\Lambda_{2}+\ldots . .+\Lambda_{\mathrm{M}-\mathrm{N}-2}+\Lambda_{\mathrm{M}-\mathrm{N}-1}+\Lambda_{\mathrm{M}-\mathrm{N}}+\mathrm{U}_{\mathrm{N}}+\ldots$ $\ldots+\Lambda_{\mathrm{M}-2}+\mathrm{U}_{2}+\Lambda_{\mathrm{M}-1}+\mathrm{U}_{1}=\mathcal{Q}_{1}$. The stationary vector of $\mathcal{Q}_{1}$ is $\pi$. This gives $\pi \mathcal{Q}_{1}=0$ and $\pi\left(\mathcal{Q}_{1}^{\prime}+\Lambda_{\mathrm{M}}\right)+$ $\pi \sum_{\mathrm{i}=1}^{\mathrm{M}-\mathrm{N}-1} \Lambda_{\mathrm{i}}+\pi \sum_{\mathrm{i}=1}^{\mathrm{N}}\left(\Lambda_{\mathrm{M}-\mathrm{i}}+\mathrm{U}_{\mathrm{i}}\right)=0$ which implies $(\pi, \pi \ldots \pi, \pi) . \mathrm{W}=0=(\pi, \pi \ldots \pi, \pi) \mathrm{W}^{\prime}$ where $\mathrm{W}$ ' is the transpose column vector of W. Since all blocks, in any block-row are seen somewhere in each and every column block due to block circulant structure, the above equation shows the left eigen vector of the matrix $\mathcal{Q}_{\mathrm{A}}^{\prime \prime}$ is $(\pi, \pi \ldots \pi)$. Using $(14)$

$\mathrm{W}=\left(\frac{\pi}{\mathrm{M}}, \frac{\pi}{\mathrm{M}}, \frac{\pi}{\mathrm{M}}, \ldots, \frac{\pi}{\mathrm{M}}\right)$.

Neuts [7], gives the stability condition as, $\mathrm{wA}_{0} \mathrm{e}<w \mathrm{~A}_{2}$ e where $\mathrm{w}$ is given by (15). Taking the sumof the same cross diagonally using the structure in (8) and (9)for the $\mathrm{A}_{0}$ and $\mathrm{A}_{2}$ matrices, it can be seen that

$\mathrm{wA}_{0} \mathrm{e}=\frac{1}{\mathrm{M}} \pi\left(\sum_{\mathrm{n}=1}^{\mathrm{M}} \mathrm{n} \Lambda_{\mathrm{n}}\right) \mathrm{e}=\frac{1}{\mathrm{M}} \pi \cdot\left(\lambda_{1} \mathrm{E}\left(\chi_{1}\right), \lambda_{2} \mathrm{E}\left(\chi_{2}\right), \ldots, \lambda_{\mathrm{k}} \mathrm{E}\left(\chi_{\mathrm{k}}\right)\right)<\mathrm{w} \mathrm{A} \mathrm{A}_{2} \mathrm{e}=\frac{1}{\mathrm{M}} \pi\left(\sum_{\mathrm{n}=1}^{\mathrm{N}} \mathrm{nU} \mathrm{U}_{\mathrm{n}}\right) \mathrm{e}$ $=\frac{1}{\mathrm{M}} \pi \cdot\left(\mu_{1} \mathrm{E}\left(\psi_{1}\right), \mu_{2} \mathrm{E}\left(\psi_{2}\right), \ldots, \mu_{\mathrm{k}} \mathrm{E}\left(\psi_{\mathrm{k}}\right)\right)$. Taking the probability vector of the environment generator $\mathcal{Q}_{1}$ as $\pi=$ $\left(\pi_{1}, \pi_{2}, \ldots, \pi_{\mathrm{k}-1}, \pi_{\mathrm{k}}\right) \quad$, the inequality reduces to $\sum_{\mathrm{i}=1}^{\mathrm{k}} \pi_{\mathrm{i}} \lambda_{\mathrm{i}} \mathrm{E}\left(\chi_{\mathrm{i}}\right)<\sum_{\mathrm{i}=1}^{\mathrm{k}} \pi_{\mathrm{i}} \mu_{\mathrm{i}} \mathrm{E}\left(\psi_{\mathrm{i}}\right) .(16)$ This is the stability condition for $\mathrm{M} / \mathrm{M} / 1$ random environment bulk arrival and bulk service queue where maximum of the maximums of arrival sizes in all environments is greater than the maximum of the maximums of service sizes in all environments. By (16), the stationary distribution exists as proved in Neuts [7].

Let $\pi(n, j, i)$, for $1 \leq j \leq M-1,0 \leq \mathrm{i} \leq \mathrm{k}$ and $0 \leq \mathrm{n}<\infty$ be the stationary probability of the states in $(1)$ and $\pi_{\mathrm{n}}$ be the vector of type $1 \times x_{k}$ with, $\pi_{n}=(\pi(n, 0,1), \pi(n, 0,2) \ldots \pi(n, 0, k), \pi(n, 1,1), \pi(n, 1,2), \ldots \pi(n, 1, k), \ldots \pi(n$, $\mathrm{M}-1,1), \pi(\mathrm{n}, \mathrm{M}-1,2) \ldots \pi(\mathrm{n}, \mathrm{M}-1, \mathrm{k}))$ for $\mathrm{n} \geq 0$.

The stationary probability vector $\pi=\left(\pi_{0}, \pi_{1}, \pi_{3}, \ldots \ldots\right)$ satisfies $\pi \mathrm{Q}_{\mathrm{A}}=0$, and $\pi \mathrm{e}=1$.

From (17), it can be seen $\pi_{0} B_{1}+\pi_{1} A_{2}=0$.

$\pi_{n-1} A_{0}+\pi_{n} A_{1}+\pi_{n+1} A_{2}=0$, for $n \geq 1$.

Introducing the rate matrix $\mathrm{R}$ as the minimal non-negative solution of the non-linear matrix equation $\mathrm{A}_{0}+\mathrm{RA}_{1}+\mathrm{R}^{2} \mathrm{~A}_{2}=0$

it can be proved (Neuts [7]) that $\pi_{n}$ satisfies $\pi_{n}=\pi_{0} R^{n} \quad$ for $n \geq 1$.

Using (17) and (21), $\pi_{0}$ satisfies $\pi_{0}\left[\mathrm{~B}_{1}+\mathrm{RA}_{2}\right]=0$

The vector $\pi_{0}$ can be calculated up to multiplicative constant by (22). From (17) and (21) $\pi_{0}(\mathrm{I}-\mathrm{R})^{-1} \mathrm{e}=1$. (23) Replacing the first column of the matrix multiplier of $\pi_{0}$ in equation (22) by the column vector multiplier of $\pi_{0}$ in (23), a matrix which is invertible may be obtained. The first row of the inverse of that same matrix is $\pi_{0}$ and this gives along with (21) all the stationary probabilities of the system. The matrix R given in (20) is computed by substitutions in the recurrence relation

$\mathrm{R}(0)=0 ; \mathrm{R}(\mathrm{n}+1)=-\mathrm{A}_{0} \mathrm{~A}_{1}^{-1}-\mathrm{R}^{2}(\mathrm{n}) \mathrm{A}_{2} \mathrm{~A}_{1}^{-1}, \mathrm{n} \geq 0$.

The iteration may be terminated to get a solution of $R$ at an approximate level where $\|R(n+1)-R(n)\|<\varepsilon$ where $\varepsilon$ is very small number. 


\subsection{Performance Measures}

(1) The probability $P(S=n)$, of the queue length $S=n$, can be seen as follows. Let $k \geq 0$ and $j$ for $0 \leq j \leq M$ be non-negative integers such that $\mathrm{n}=\mathrm{k} \mathrm{M}+\mathrm{j}$. Then using (21) (22) and (23)it is noted that $\mathrm{P}(\mathrm{S}=\mathrm{n})$ $=\sum_{\mathrm{i}=1}^{\mathrm{k}} \pi \quad(\mathrm{k}, \mathrm{j}, \mathrm{i})$, where $\mathrm{n}=\mathrm{k} \mathrm{M}+\mathrm{j}$.(2) $\mathrm{P}$ (Queue length is 0$)=\mathrm{P}(\mathrm{S}=0)=\sum_{\mathrm{i}=1}^{\mathrm{k}} \pi(0,0, \mathrm{i})$. (3) The expected queue level E(S), can be calculated as follows. Since $\pi(n, j, i)=P[S=M n+j$, and environment state $=\mathrm{i}$ ], for $\mathrm{n} \geq 0$, and $1 \leq \mathrm{j} \leq \mathrm{M}-1$ and $1 \leq \mathrm{i} \leq \mathrm{k}$, we find $\mathrm{E}(\mathrm{S})=\sum_{\mathrm{n}=0}^{\infty} \sum_{\mathrm{j}=0}^{\mathrm{M}-1} \sum_{\mathrm{i}=1}^{\mathrm{k}} \pi(\mathrm{n}, \mathrm{j}, \mathrm{i})(\mathrm{Mn}+$ $\mathrm{j}=\mathrm{n}=0 \infty \pi \mathrm{n} .(\mathrm{Mn} \ldots \mathrm{Mn}, \mathrm{Mn}+1 \ldots \mathrm{Mn}+1, \mathrm{Mn}+2 \ldots \mathrm{Mn}+2 \ldots \mathrm{Mn}+\mathrm{M}-1 \ldots \mathrm{Mn}+\mathrm{M}-1)$ where in the multiplier vector $\mathrm{Mn}$ appears $\mathrm{k}$ times, $\mathrm{Mn}+1$ appears $\mathrm{k}$ times and so on and finally $\mathrm{Mn}+\mathrm{M}-1$ appears $\mathrm{k}$ times. So $\mathrm{E}(\mathrm{S})$ $=\mathrm{M} \sum_{\mathrm{n}=0}^{\infty} \mathrm{n} \pi_{\mathrm{n}} \mathrm{e}+\pi_{0}(\mathrm{I}-\mathrm{R})^{-1} \xi$. Here $\mathrm{Mk} x 1$ column vector $\xi=(0, \ldots 0,1, \ldots, 1,2, \ldots, 2, \ldots, \mathrm{M}-1, \ldots, \mathrm{M}-1)^{\prime}$. So $\mathrm{E}(\mathrm{S})=\pi_{0}(\mathrm{I}-\mathrm{R})^{-1} \xi+\mathrm{M} \pi_{0}(\mathrm{I}-\mathrm{R})^{-2} \mathrm{Re}$

(4) Variance of queue level can be seen using Variance $(S)=E\left(S^{2}\right)-E(S)^{2}$. Let $\eta$ be column vector $\eta=\left[0, . .0,1^{2}, \ldots 1^{2} 2^{2}, \ldots 2^{2}, \ldots(M-1)^{2}, \ldots(M-1)^{2}\right]^{\prime}$ of type Mkx1. Then it can be seen that the second moment, $\mathrm{E}\left(\mathrm{S}^{2}\right)=\sum_{\mathrm{n}=0}^{\infty} \sum_{\mathrm{J}=0}^{\mathrm{M}-1} \sum_{\mathrm{i}=1}^{\mathrm{k}} \pi(\mathrm{n}, \mathrm{j}, \mathrm{i})[\mathrm{M} \mathrm{n}+\mathrm{j}]^{2}=\mathrm{M}^{2}\left[\sum_{\mathrm{n}=1}^{\infty} \mathrm{n}(\mathrm{n}-1) \pi_{\mathrm{n}} \mathrm{e}+\sum_{\mathrm{n}=0}^{\infty} \mathrm{n} \pi_{\mathrm{n}} \mathrm{e}\right]+\sum_{\mathrm{n}=0}^{\infty} \pi_{\mathrm{n}} \eta+$ $2 \mathrm{M} \sum_{\mathrm{n}=0}^{\infty} \mathrm{n} \pi_{\mathrm{n}} \xi$. So, $\mathrm{E}\left(\mathrm{S}^{2}\right)=\mathrm{M}^{2}\left[\pi_{0}(\mathrm{I}-\mathrm{R})^{-3} 2 \mathrm{R}^{2} \mathrm{e}+\pi_{0}(\mathrm{I}-\mathrm{R})^{-2} \mathrm{Re}\right]+\pi_{0}(\mathrm{I}-\mathrm{R})^{-1} \eta+2 \mathrm{M} \pi_{0}(\mathrm{I}-\mathrm{R})^{-2} \mathrm{R} \xi$ Using (25) and (26) variance can be written.

\section{Maximum Arrival Size $M$ is Less Than the Maximum Service Size $\mathbf{N}$}

In this Model (B) the dual case of Model (A), namely the case, $\mathrm{M}<\mathrm{N}$ is treated. (When $\mathrm{M}=\mathrm{N}$ both models are applicable and one can use any one of them.) The assumption (v) of Model (A) is modified and all its other assumptions are unchanged.

\subsection{Assumption.}

v) The maximum of the maximums of arrival sizes in all the environments $M=\max _{1 \leq s \leq k} M_{i} i$ less than the maximum of the maximums of service sizes in all the environments $N=\max _{1 \unlhd s k} N_{i}$ where the maximum arrival and service sizes $\operatorname{are}_{\mathrm{i}}$ and $\mathrm{N}_{\mathrm{i}}$ in the environment $\mathrm{i}$ for $1 \leq \mathrm{i} \leq \mathrm{k}$.

\subsection{Analysis}

Since this model is dual, the analysis is same as that of Model (A). The differences are noted below. The state space of the chain is as follows defined in a similar way.

$\mathrm{X}(\mathrm{t})=\{(\mathrm{n}, \mathrm{j}, \mathrm{i})$ : for $0 \leq \mathrm{j} \leq \mathrm{N}-1$ for $1 \leq \mathrm{i} \leq \mathrm{k}$ and $0 \leq \mathrm{n}<\infty\}$.

The chain is in the state (n, j, i) when the number of customers in the queue is, $n \mathrm{~N}+\mathrm{j}$, and the environment state is $\mathrm{i}$ for $1 \leq \mathrm{j} \leq \mathrm{N}-1$, for $0 \leq \mathrm{i} \leq \mathrm{k}$ and $0 \leq \mathrm{n}<\infty$. When the customers in the system is $\mathrm{k}$ then $\mathrm{k}$ is identified with $(n, j)$ where $k$ on division by $\mathrm{N}$ gives $\mathrm{n}$ as the quotient and $\mathrm{j}$ as the remainder.

The infinitesimal generator $Q_{B}$ of the model has the same block partitioned structure given in (4) for Model (A) but the inner matrices are of different orders and elements.

$\mathrm{Q}_{\mathrm{B}}=\left[\begin{array}{cccccccc}\mathrm{B}_{1}^{\prime} & \mathrm{A}_{0}^{\prime} & 0 & 0 & . & . & . & \cdots \\ \mathrm{A}_{2}^{\prime} & \mathrm{A}_{1}^{\prime} & \mathrm{A}_{0}^{\prime} & 0 & . & . & . & \cdots \\ 0 & \mathrm{~A}_{2}^{\prime} & \mathrm{A}_{1}^{\prime} & \mathrm{A}_{0}^{\prime} & 0 & . & . & \cdots \\ 0 & 0 & \mathrm{~A}_{2}^{\prime} & \mathrm{A}_{1}^{\prime} & \mathrm{A}_{0}^{\prime} & 0 & . & \cdots \\ 0 & 0 & 0 & \mathrm{~A}_{2}^{\prime} & \mathrm{A}_{1}^{\prime} & \mathrm{A}_{0}^{\prime} & 0 & \cdots \\ \vdots & \vdots & \vdots & \vdots & \ddots & \ddots & \ddots & \ddots\end{array}\right]$

In (28) the states of the matrices are listed lexicographically as $\underline{0}, \underline{1}, \underline{2}, \underline{3}, \ldots . \underline{\mathrm{n}}, \ldots$. Here the state vector is given as follows. $\underline{n}=((\mathrm{n}, 0,1), \ldots(\mathrm{n}, 0, \mathrm{k}),(\mathrm{n}, 1,1), \ldots(\mathrm{n}, 1, \mathrm{k}),(\mathrm{n}, 2,1), \ldots(\mathrm{n}, 2, \mathrm{k}), \ldots(\mathrm{n}, \mathrm{N}-1,1), \ldots(\mathrm{n}, \mathrm{N}-1, \mathrm{k}))$, for $0 \leq \mathrm{n}$ $<\infty$. The matrices, $\mathrm{B}_{1}^{\prime}, \mathrm{A}_{0}^{\prime}, \mathrm{A}_{1}^{\prime}$ and $\mathrm{A}_{2}{ }_{2}$ are all of order $\mathrm{Nk}$. The matrices $\mathrm{B}_{1}^{\prime}$ and $\mathrm{A}_{1}^{\prime}$ have negative diagonal elements and their off diagonal elements are non- negative. The matrices $\mathrm{A}_{0}^{\prime}$ and $\mathrm{A}_{2}^{\prime}$ have nonnegative elements. They are all given below. As in model (A), letting $\Lambda_{\mathrm{j}}$, for $1 \leq \mathrm{j} \leq \mathrm{M}$, and $\mathrm{U}_{\mathrm{j}}, \mathrm{V}_{\mathrm{j}}$ for $1 \leq \mathrm{j} \leq \mathrm{N}, \Lambda$ and $\mathrm{U}$ as diagonal matrices of order $\mathrm{k}$ given by (5) and (6) and letting $Q_{1}^{\prime}=Q_{1}-\Lambda-\mathrm{U}$, the partitioning matrices are defined as follows 
$\mathrm{A}_{0}^{\prime}$
$=\left[\begin{array}{cccccccc}0 & 0 & \cdots & 0 & 0 & 0 & \cdots & 0 \\ \vdots & \vdots & \cdots & \vdots & \vdots & \vdots & \vdots & \vdots \\ 0 & 0 & \cdots & 0 & 0 & 0 & \cdots & 0 \\ \Lambda_{\mathrm{M}} & 0 & \cdots & 0 & 0 & 0 & \cdots & 0 \\ \Lambda_{\mathrm{M}-1} & \Lambda_{\mathrm{M}} & \cdots & 0 & 0 & 0 & \cdots & 0 \\ \vdots & \vdots & \ddots & \vdots & \vdots & \vdots & \vdots & \vdots \\ \Lambda_{2} & \Lambda_{3} & \cdots & \Lambda_{\mathrm{M}} & 0 & 0 & \cdots & 0 \\ \Lambda_{1} & \Lambda_{2} & \cdots & \Lambda_{\mathrm{M}-1} & \Lambda_{\mathrm{M}} & 0 & \cdots & 0\end{array}\right](29)$

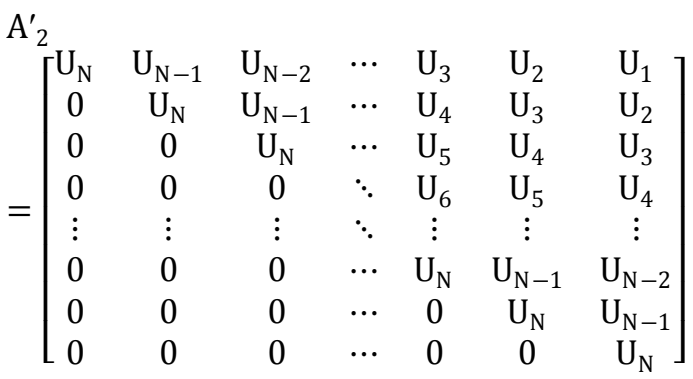

$$
\mathrm{A}_{1}^{\prime}=\left[\begin{array}{cccccccccc}
\mathcal{Q}_{1}^{\prime} & \Lambda_{1} & \Lambda_{2} & \cdots & \Lambda_{\mathrm{M}} & 0 & 0 & \cdots & 0 & 0 \\
\mathrm{U}_{1} & Q_{1}^{\prime} & \Lambda_{1} & \cdots & \Lambda_{\mathrm{M}-1} & \Lambda_{\mathrm{M}} & 0 & \cdots & 0 & 0 \\
\mathrm{U}_{2} & \mathrm{U}_{1} & \mathcal{Q}_{1}^{\prime} & \cdots & \Lambda_{\mathrm{M}-2} & \Lambda_{\mathrm{M}-1} & \Lambda_{\mathrm{M}} & \cdots & 0 & 0 \\
\vdots & \vdots & \vdots & \ddots & \vdots & \vdots & \vdots & \ddots & \vdots & \vdots \\
\mathrm{U}_{\mathrm{N}-\mathrm{M}-1} & \mathrm{U}_{\mathrm{N}-\mathrm{M}-2} & \mathrm{U}_{\mathrm{N}-\mathrm{M}-3} & \cdots & \mathcal{Q}_{1}^{\prime} & \Lambda_{1} & \Lambda_{2} & \cdots & \Lambda_{\mathrm{M}-1} & \Lambda_{\mathrm{M}} \\
\mathrm{U}_{\mathrm{N}-\mathrm{M}} & \mathrm{U}_{\mathrm{N}-\mathrm{M}-1} & \mathrm{U}_{\mathrm{N}-\mathrm{M}-2} & \cdots & \mathrm{U}_{1} & \mathcal{Q}_{1}^{\prime} & \Lambda_{1} & \cdots & \Lambda_{\mathrm{M}-2} & \Lambda_{\mathrm{M}-1} \\
\mathrm{U}_{\mathrm{N}-\mathrm{M}+1} & \mathrm{U}_{\mathrm{N}-\mathrm{M}} & \mathrm{U}_{\mathrm{N}-\mathrm{M}-1} & \cdots & \mathrm{U}_{2} & \mathrm{U}_{1} & Q_{1}^{\prime} & \cdots & \Lambda_{\mathrm{M}-3} & \Lambda_{\mathrm{M}-2} \\
\vdots & \vdots & \vdots & \ddots & \vdots & \vdots & \vdots & \ddots & \vdots & \vdots \\
\mathrm{U}_{\mathrm{N}-2} & \mathrm{U}_{\mathrm{N}-3} & \mathrm{U}_{\mathrm{N}-4} & \cdots & \mathrm{U}_{\mathrm{N}-\mathrm{M}-2} & \mathrm{U}_{\mathrm{N}-\mathrm{M}-3} & \mathrm{U}_{\mathrm{N}-\mathrm{M}-2} & \cdots & Q_{1}^{\prime} & \Lambda_{1} \\
\mathrm{U}_{\mathrm{N}-1} & \mathrm{U}_{\mathrm{N}-2} & \mathrm{U}_{\mathrm{N}-3} & \cdots & \mathrm{U}_{\mathrm{N}-\mathrm{M}-1} & \mathrm{U}_{\mathrm{N}-\mathrm{M}-2} & \mathrm{U}_{\mathrm{N}-\mathrm{M}-1} & \cdots & \mathrm{U}_{1} & \mathcal{Q}_{1}^{\prime}
\end{array}\right]
$$

$\mathrm{B}^{\prime}{ }_{1}=\left[\begin{array}{cccccccccc}\mathcal{Q}_{1}-\Lambda & \Lambda_{1} & \Lambda_{2} & \cdots & \Lambda_{\mathrm{M}} & 0 & 0 & \cdots & 0 & 0 \\ \mathrm{U} & \mathcal{Q}_{1}^{\prime} & \Lambda_{1} & \cdots & \Lambda_{\mathrm{M}-1} & \Lambda_{\mathrm{M}} & 0 & \cdots & 0 & 0 \\ \mathrm{~V}_{1} & \mathrm{U}_{1} & \mathcal{Q}_{1}^{\prime} & \cdots & \Lambda_{\mathrm{M}-2} & \Lambda_{\mathrm{M}-1} & \Lambda_{\mathrm{M}} & \cdots & 0 & 0 \\ \vdots & \vdots & \vdots & \ddots & \vdots & \vdots & \vdots & \ddots & \vdots & \vdots \\ \mathrm{V}_{\mathrm{N}-\mathrm{M}-2} & \mathrm{U}_{\mathrm{N}-\mathrm{M}-2} & \mathrm{U}_{\mathrm{N}-\mathrm{M}-3} & \cdots & \mathcal{Q}_{1}^{\prime} & \Lambda_{1} & \Lambda_{2} & \cdots & \Lambda_{\mathrm{M}-1} & \Lambda_{\mathrm{M}} \\ \mathrm{V}_{\mathrm{N}-\mathrm{M}-1} & \mathrm{U}_{\mathrm{N}-\mathrm{M}-1} & \mathrm{U}_{\mathrm{N}-\mathrm{M}-2} & \cdots & \mathrm{U}_{1} & \mathcal{Q}_{1}^{\prime} & \Lambda_{1} & \cdots & \Lambda_{\mathrm{M}-2} & \Lambda_{\mathrm{M}-1} \\ \mathrm{~V}_{\mathrm{N}-\mathrm{M}} & \mathrm{U}_{\mathrm{N}-\mathrm{M}} & \mathrm{U}_{\mathrm{N}-\mathrm{M}-1} & \cdots & \mathrm{U}_{2} & \mathrm{U}_{1} & Q_{1}^{\prime} & \cdots & \Lambda_{\mathrm{M}-3} & \Lambda_{\mathrm{M}-2} \\ \vdots & \vdots & \vdots & \ddots & \vdots & \vdots & \vdots & \ddots & \vdots & \vdots \\ \mathrm{V}_{\mathrm{N}-3} & \mathrm{U}_{\mathrm{N}-3} & \mathrm{U}_{\mathrm{N}-4} & \cdots & \mathrm{U}_{\mathrm{N}-\mathrm{M}-2} & \mathrm{U}_{\mathrm{N}-\mathrm{M}-3} & \mathrm{U}_{\mathrm{N}-\mathrm{M}-2} & \cdots & \mathcal{Q}_{1}^{\prime} & \Lambda_{1} \\ \mathrm{~V}_{\mathrm{N}-2} & \mathrm{U}_{\mathrm{N}-2} & \mathrm{U}_{\mathrm{N}-3} & \cdots & \mathrm{U}_{\mathrm{N}-\mathrm{M}-1} & \mathrm{U}_{\mathrm{N}-\mathrm{M}-2} & \mathrm{U}_{\mathrm{N}-\mathrm{M}-1} & \cdots & \mathrm{U}_{1} & \mathcal{Q}_{1}^{\prime}\end{array}\right]$ $Q_{B}^{\prime \prime}=$

$\left[\begin{array}{ccccc}\mathcal{Q}_{1}^{\prime}+U_{N} & \Lambda_{1}+U_{N-1} & \cdots & \Lambda_{M-1}+U_{N-M+1} & \Lambda_{M}+U_{N-M} \\ U_{1} & \mathcal{Q}_{1}^{\prime}+U_{N} & \cdots & \Lambda_{M-2}+U_{N-M+2} & \Lambda_{M-1}+U_{N-M+1} \\ \vdots & \vdots & \vdots \vdots \vdots & \vdots & \vdots \\ U_{N-M-2} & U_{N-M-3} & \cdots & Q_{1}^{\prime}+U_{N} & \Lambda_{1}+U_{N-1} \\ U_{N-M-1} & U_{N-M-2} & \cdots & U_{1} & Q_{1}^{\prime}+U_{N} \\ \Lambda_{M}+U_{N-M} & U_{N-M-1} & \cdots & U_{2} & U_{1} \\ \vdots & \vdots & \vdots \vdots & \vdots & \vdots \\ \Lambda_{2}+U_{N-2} & \Lambda_{3}+U_{N-3} & \cdots & U_{N-M-1} & U_{N-M-2} \\ \Lambda_{1}+U_{N-1} & \Lambda_{2}+U_{N-2} & \cdots & \Lambda_{M}+U_{N-M} & U_{N-M-1}\end{array}\right.$

$$
\begin{array}{cc}
U_{N-M-1} & \cdots \\
\Lambda_{M}+U_{N-M} & \cdots \\
\vdots & \vdots \vdots \\
\Lambda_{2}+U_{N-2} & \cdots \\
\Lambda_{1}+U_{N-1} & \cdots \\
Q_{1}^{\prime}+U_{N} & \cdots \\
\vdots & \vdots \vdots \\
U_{N-M-3} & \cdots \\
U_{N-M-2} & \cdots
\end{array}
$$$$
\begin{gathered}
U_{2} \\
U_{3} \\
\vdots \\
\Lambda_{M}+U_{N-M} \\
\Lambda_{M-1}+U_{N-M+1} \\
\Lambda_{M-2}+U_{N-M+2} \\
\vdots \\
Q_{1}^{\prime}+U_{N} \\
U_{1}
\end{gathered}
$$$$
\left.\begin{array}{c}
U_{1} \\
U_{2} \\
\vdots \\
U_{N-M-1} \\
\Lambda_{M}+U_{N-M} \\
\Lambda_{M-1}+U_{N-M+1} \\
\vdots \\
\Lambda_{1}+U_{N-1} \\
\mathcal{Q}_{1}^{\prime}+U_{N}
\end{array}\right]
$$

The basic generator which is concerned with only the arrival and service is $Q_{\mathrm{B}}^{\prime \prime}$ circulant. Using similar arguments given for Model (A) it can be seen that its probability vector is $\left(\frac{\pi}{N}, \frac{\pi}{N}, \frac{\pi}{N}, \ldots, \frac{\pi}{N}\right)$ and the stability condition remains the same. Following the arguments given for Model (A), one can find the stationary probability vector for Model (B) also in matrix geometric form. All performance measures given in section 2.3 including the expectation of customers waiting for service and its variance for Model (B) have the same form as given in Model (A) except M is replaced by N.

\section{M/PH/1and PH/M/1 Bulk Arrival and Bulk Service Queues}

In this section $\mathrm{M} / \mathrm{PH} / 1$ and $\mathrm{PH} / \mathrm{M} / 1$ bulk arrival and bulk service queues are studied. Here the varying environment phase discussed earlier is identified with the phase of the $\mathrm{PH}$ generator. The same analysis and the partition structure can be used to study the bulk arrival and bulk service $\mathrm{M} / \mathrm{PH} / 1$ and $\mathrm{PH} / \mathrm{M} / 1$ queues. They are presented below. Only important steps are explained.

\subsection{M/PH/1Bulk Arrival and Bulk Service Queue}

For M/PH/1 bulk arrival and bulk service queue letp $\mathrm{p}_{\mathrm{j}}^{\mathrm{i}}$ and $\mathrm{q}_{\mathrm{n}}^{\mathrm{i}}$ be the probabilities of bulk arrival size is $\mathrm{j}$ for $1 \leq \mathrm{j}$ $\leq \mathrm{M}$ and bulk service size is $\mathrm{n}$ for $1 \leq \mathrm{n} \leq \mathrm{N}$, when the $\mathrm{PH}$ phase is $\mathrm{i}, 1 \leq \mathrm{i} \leq \mathrm{k}$ taking the both bulk sizes 
(including the arrival) are depending on the PH service phase. Let the PH distribution be given by $(\underline{\alpha}, \mathrm{T})$ where the starting vector is $\underline{\alpha}=\left(\alpha_{1}, \alpha_{2} \ldots . \alpha_{\mathrm{k}}\right)$ and $\sum_{\mathrm{i}=1}^{\mathrm{k}} \alpha_{\mathrm{i}}=1$ and the absorption rate column vector $\operatorname{isT}_{0}=-\mathrm{T} \mathrm{e}$ $=\left(t_{1}, t_{2}, \ldots t_{k}\right)^{\prime}$. The above bulk partition method may be used for studying this queue. The matrices are slightly modified. Taking the arrival rate is $\lambda_{\mathrm{i}}$, when the PH service phase is $\mathrm{i}$ for $1 \leq \mathrm{i} \leq \mathrm{k}$, in the following way the previous matrices are defined.

$\Lambda_{j}=\operatorname{diag}\left(\lambda_{1} p_{j}^{1}, \lambda_{2} p_{j}^{2}, \ldots, \lambda_{k} p_{j}^{k}\right) \quad$ for $1 \leq j \leq M, U_{j}=\left(t_{1} q_{j}^{1}, t_{2} q_{j}^{2}, \ldots, t_{k} q_{j}^{k}\right)^{\prime} \underline{\alpha f o r} 1 \leq j \leq N, V_{j}=$ $\left(\mathrm{t}_{1} \mathrm{Q}_{\mathrm{j}}^{1}, \mathrm{t}_{2} \mathrm{Q}_{\mathrm{j}}^{2}, \ldots, \mathrm{t}_{\mathrm{k}} \mathrm{Q}_{\mathrm{j}}^{\mathrm{k}}\right) \underline{\alpha}$, for $1 \leq \mathrm{j} \leq \mathrm{N}, \Lambda=\operatorname{diag}\left(\lambda_{1}, \lambda_{2}, \ldots, \lambda_{\mathrm{k}}\right)$ and $\mathrm{U}=\mathrm{T}_{0} \underline{\alpha}$.

Matrices $Q_{1}$ and $Q_{2}^{\prime}$ are now defined as $Q_{1}=\mathrm{T}+\mathrm{T}_{0} \underline{\alpha}$ and $Q_{1}^{\prime}=\mathrm{T}-\Lambda$. The analysis given above for the two models $\mathrm{M}>\mathrm{N}$ and $\mathrm{N}>\mathrm{M}$, the block partitions of the infinite order generators presented, the circulant structures of the basic system generators and the performance measures seen are all valid. When $\pi$ is probability vector of $Q_{1}=\mathrm{T}+\mathrm{T}_{0} \underline{\alpha}$ of the $\mathrm{PH}$ generator of the PH service distribution, then the basic system generator has invariant probability vector as $\left(\frac{\pi}{\mathrm{M}}, \frac{\pi}{\mathrm{M}}, \frac{\pi}{\mathrm{M}}, \ldots, \frac{\pi}{\mathrm{M}}\right)$.The stability condition becomes

$\sum_{\mathrm{i}=1}^{\mathrm{k}} \pi_{\mathrm{i}} \lambda_{\mathrm{i}} \mathrm{E}\left(\chi_{\mathrm{i}}\right)<\sum_{\mathrm{i}=1}^{\mathrm{k}} \pi_{\mathrm{i}} \mathrm{t}_{\mathrm{i}} \mathrm{E}\left(\psi_{\mathrm{i}}\right)$.

Here $\mathrm{E}\left(\chi_{\mathrm{i}}\right)$ and $\mathrm{E}\left(\psi_{\mathrm{i}}\right)$ are expected bulk arrival and bulk service sizes in PH phase $1 \leq \mathrm{i} \leq \mathrm{k}$ and $\pi=$ $\left(\pi_{1}, \pi_{2}, \ldots, \pi_{\mathrm{k}-1}, \pi_{\mathrm{k}}\right)$ is the invariant probability vector of the $\mathrm{PH}$ generator.

\section{2. $\mathrm{PH} / \mathrm{M} / 1$ Bulk Arrival and Bulk Service Queue}

For PH/M/1bulk arrival and bulk service queue with same probabilities of bulk arrivals and bulk service sizes and the PH distribution given above, the same method can be used. Taking the service rate $\mu_{\mathrm{i}}$, when the PH arrival phase is $\mathrm{i}$, for $1 \leq \mathrm{i} \leq \mathrm{k}$, the following the matrices are defined.

$\Lambda_{j}=\left(t_{1} p_{j}^{1}, t_{2} p_{j}^{2}, \ldots, t_{k} p_{j}^{k}\right)^{\prime} \underline{\alpha}$ for $1 \leq j \leq M, \Lambda=T_{0} \underline{\alpha}, \quad U_{j}=\operatorname{diag}\left(\mu_{1} q_{j}^{1}, \mu_{2} q_{j}^{2}, \ldots, \mu_{k} q_{j}^{k}\right)$ for $1 \leq j \leq N$, $\mathrm{V}_{\mathrm{j}}=\operatorname{diag}\left(\mu_{1} Q_{\mathrm{j}}^{1}, \mu_{2} Q_{\mathrm{j}}^{2}, \ldots, \mu_{\mathrm{k}} Q_{\mathrm{j}}^{\mathrm{k}}\right)$ for $1 \leq \mathrm{j} \leq \mathrm{N}, \mathrm{U}=\operatorname{diag}\left(\mu_{1}, \mu_{2}, \ldots, \mu_{\mathrm{k}}\right), \quad Q_{1}^{\prime}=\mathrm{T}-\mathrm{U}$ and $Q_{1}=\mathrm{T}+\mathrm{T}_{0} \underline{\alpha}$. The analysis given above for the two models $\mathrm{M}>\mathrm{N}$ and $\mathrm{N}>\mathrm{M}$, the block partitions of the infinite order generators, the circulant structures of the basic system generators and the performance measures seen are all valid. The stability condition is $\sum_{\mathrm{i}=1}^{\mathrm{k}} \pi_{\mathrm{i}} \mathrm{t}_{\mathrm{i}} \mathrm{E}\left(\chi_{\mathrm{i}}\right)<\sum_{\mathrm{i}=1}^{\mathrm{k}} \pi_{\mathrm{i}} \mu_{\mathrm{i}} \mathrm{E}\left(\psi_{\mathrm{i}}\right)$ where $\mathrm{E}\left(\chi_{\mathrm{i}}\right)$ and $\mathrm{E}\left(\psi_{\mathrm{i}}\right)$ are expected bulk arrival and bulk service sizes in $\mathrm{PH}$ phase $\mathrm{i}, 1 \leq \mathrm{i} \leq \mathrm{k}$.

The models, in which, the arrival pattern are not depending on $\mathrm{PH}$ service phase in M/PH/1 queue and the service pattern are not depending on $\mathrm{PH}$ arrival phase in $\mathrm{PH} / \mathrm{M} / 1$ queue, are special cases of the models considered

\section{Numerical Illustration}

For Model (A), the varying environment is considered to be governed by the Matrix $\mathcal{Q}_{1}=\left[\begin{array}{ccc}-3 & 2 & 1 \\ 1 & -3 & 2 \\ 2 & 1 & -3\end{array}\right]$. The maximum of the maximums of all bulk arrival sizes for all environments, $\mathrm{M}$ is fixed as 4 and the maximum of the maximums of all bulk service sizes for all environments, $\mathrm{N}$ is fixed as 2 . The probabilities of the bulk arrivals of various sizes $1,2,3$, and 4 in the three environments are considered respectively $(.5,3,1,1,1)$, $(.7, .2, .1,0)$, and $(.8,2,0,0)$ and the probabilities of the bulk service of various sizes $1,2,3$, and 4 in the environments are considered respectively $(.5, .5,0,0),(.6, .4,0,0)$ and $(.7, .3,0,0)$. In table1 the various probabilities queue length at levels $0,1,2,3$, in between0and 3 , in between 4 and 7 , in between 8 and 11, in between 13 and 16, and greater than 17 are tabulated in three columns by first fixing the service rates in the three environments as $(4,5,6)$ and by varying the arrival rates as $(3,4,5),(2,3,4)$ and $(1,2,3)$. In a similar way by fixing the arrival rates in the three environments as $(4,5,6)$ and by varying the service rates as $(5,6,7)$, $(6,7,8)$ and $(7,8,9)$ results are obtained and listed in three last columns. Here same number of 30 iterations are performed to find the rate matrix $\mathrm{R}$ in all cases. When the service rate is fixed as $(4,5,6)$ and the arrival rates decrease, the probability of empty queue increases, the difference-norm of the convergence of the rate matrix for same 30 iterations decreases, expected values of queue length and its variances also decrease. It can also be seen that the situation is same when the arrival rate is fixed as $(4,5,6)$ and service rates are varied as $(5,6,7),(6,7$, 8 ) and $(7,8,9)$. For Model (B), the varying environment is considered to be governed by the Matrix $Q_{1}=$ $\left[\begin{array}{ccc}-3 & 2 & 1 \\ 1 & -2 & 1 \\ 1 & 2 & -3\end{array}\right]$. The maximum of the maximums of all bulk arrival sizes for all environments, $M$ is fixed as 2 and the maximum of the maximums of all bulk service sizes for all environments, $\mathrm{N}$ is fixed as 4 . The probabilities of the bulk service of various sizes $1,2,3$, and 4 in the three environments are considered respectively $(.5,3,1, .1),(.7,2, .1,0)$, and $(.8, .2,0,0)$ and the probabilities of the bulk arrivals of various sizes 1 , 2,3 , and 4 in the environments are considered respectively $(.5, .5,0,0),(.6, .4,0,0)$ and $(.7, .3,0,0)$. In table2, various probabilities of queue level $0,1,2,3$, between 0 and 3, between 4 and 7 , between 8 and 11, between 13 
and 16, and greater than 17 are tabulated in three columns by first fixing the service rates in the three environments as $(4,5,6)$ and by varying the arrival rates as $(3,4,5),(2,3,4)$ and $(1,2,3)$. In a similar way by fixing the arrival rates in the three environments as $(4,5,6)$ and by varying the service rates as $(5,6,7),(6,7,8)$ and $(7,8,9)$ results are obtained and listed in three last columns. Here same number of 30 iterations are performed to find the rate matrix $\mathrm{R}$ in all cases. When the arrival rates decrease, the probability of empty queue increases, the difference-norm of the convergence of rate matrix for same the number of 30 iterations decreases, expected values of queue length and its variances also decrease. It can also be seen the situation is same when service rates increase. Figures 1, 2, 3 and 4 present the effects of variations of arrival and service rates on probabilities and expectations.

Table 1.Model (A) Results When Arrival and Service rates Vary.

\begin{tabular}{|l|l|l|l|l|l|l|l|}
\hline $\mathrm{Ue}^{\prime}=(4,5,6)$ & $\Lambda \mathrm{e}^{\prime}=(3,4,5)$ & $\Lambda \mathrm{e}^{\prime}=(2,3,4)$ & $\Lambda \mathrm{e}^{\prime}=(1,2,3)$ & $\Lambda \mathrm{e}^{\prime}=(4,5,6)$ & $\mathrm{Ue}^{\prime},=(5,6,7)$ & $\mathrm{Ue}^{\prime}=(6,7,8)^{\prime}$ & $\mathrm{Ue}^{\prime}=(7,8,9)$ \\
\hline $\mathrm{P}(\mathrm{S}=0)$ & 0.158341371 & 0.351441621 & 0.560979439 & $\mathrm{P}(\mathrm{S}=0)$ & 0.125832135 & 0.233000621 & 0.317787225 \\
\hline $\mathrm{P}(\mathrm{S}=1)$ & 0.092424855 & 0.158874787 & 0.173652676 & $\mathrm{P}(\mathrm{S}=1)$ & 0.076007652 & 0.123401837 & 0.149704004 \\
\hline $\mathrm{P}(\mathrm{S}=2)$ & 0.084554203 & 0.124076102 & 0.109577833 & $\mathrm{P}(\mathrm{S}=2)$ & 0.071227843 & 0.106497122 & 0.120451635 \\
\hline $\mathrm{P}(\mathrm{S}=3)$ & 0.075038802 & 0.092936098 & 0.064991978 & $\mathrm{P}(\mathrm{S}=3)$ & 0.064822953 & 0.088793362 & 0.093133234 \\
\hline$\pi 0 \mathrm{e}$ & 0.410359231 & 0.727328608 & 0.909201927 & $\pi 0 \mathrm{e}$ & 0.337890582 & 0.551692942 & 0.681076098 \\
\hline$\pi 1 \mathrm{e}$ & 0.225011278 & 0.189069376 & 0.080674002 & $\pi 1 \mathrm{e}$ & 0.206643766 & 0.230973363 & 0.20473389 \\
\hline$\pi 2 \mathrm{e}$ & 0.138811418 & 0.057851069 & 0.008983862 & $\pi 2 \mathrm{e}$ & 0.14170573 & 0.111556605 & 0.072993415 \\
\hline$\pi 3 \mathrm{e}$ & 0.085949763 & 0.017815767 & 0.001011659 & $\pi 3 \mathrm{e}$ & 0.097585693 & 0.054267298 & 0.026314998 \\
\hline $\mathrm{P}(\mathrm{S}>17)$ & 0.13986831 & 0.00793518 & 0.00012855 & $\mathrm{P}(\mathrm{S}>17)$ & 0.216174229 & 0.051509793 & 0.014881599 \\
\hline Norm & $9.42 \mathrm{E}-05$ & $1.05 \mathrm{E}-07$ & $4.95 \mathrm{E}-13$ & Norm & $2.15 \mathrm{E}-04$ & $1.26 \mathrm{E}-05$ & $5.88 \mathrm{E}-07$ \\
\hline Arrival Rate & 1.416666667 & 1.05 & 0.683333333 & Arrival Rate & 1.783333333 & 1.783333333 & 1.783333333 \\
\hline Service rate & 1.733333333 & 1.733333333 & 1.733333333 & Service rate & 2.083333333 & 2.433333333 & 2.783333333 \\
\hline $\mathrm{E}(\mathrm{S})$ & 7.47240682 & 2.569412223 & 1.074481848 & $\mathrm{E}(\mathrm{S})$ & 9.833692906 & 4.660860449 & 3.036884931 \\
\hline Variance $(\mathrm{S})$ & 69.08387352 & 11.02162889 & 2.947432592 & Variance $(\mathrm{S})$ & 114.5402812 & 30.15358634 & 14.68843333 \\
\hline
\end{tabular}

Table 2.Model (B) Results When Arrival and Service rates Vary.

\begin{tabular}{|l|l|l|l|l|l|l|l|}
\hline $\mathrm{Ue}=(4,5,6)^{\prime}$ & $\Lambda \mathrm{e}=(3,4,5)^{\prime}$ & $\Lambda \mathrm{e}=(2,3,4)^{\prime}$ & $\Lambda \mathrm{e}=(1,2,3)^{\prime}$ & $\Lambda \mathrm{e}=(4,5,6)$ & $\mathrm{Ue}=(5,6,7)^{\prime}$ & $\mathrm{Ue}=(6,7,8)^{\prime}$ & $\mathrm{Ue}=(7,8,9)^{\prime}$ \\
\hline $\mathrm{P}(\mathrm{S}=0)$ & 0.179914796 & 0.357761922 & 0.554165978 & $\mathrm{P}(\mathrm{S}=0)$ & 0.153049652 & 0.254328475 & 0.334056358 \\
\hline $\mathrm{P}(\mathrm{S}=1)$ & 0.100656184 & 0.156789871 & 0.168524782 & $\mathrm{P}(\mathrm{S}=1)$ & 0.088354101 & 0.129274956 & 0.151706226 \\
\hline $\mathrm{P}(\mathrm{S}=2)$ & 0.103084273 & 0.141038455 & 0.127877761 & $\mathrm{P}(\mathrm{S}=2)$ & 0.092287239 & 0.126033335 & 0.139586554 \\
\hline $\mathrm{P}(\mathrm{S}=3)$ & 0.083766589 & 0.093776814 & 0.06345717 & $\mathrm{P}(\mathrm{S}=3)$ & 0.076959324 & 0.094550266 & 0.095317428 \\
\hline$\pi 0 \mathrm{e}$ & 0.467421842 & 0.749367062 & 0.914025691 & $\pi 0 \mathrm{e}$ & 0.410650315 & 0.604187032 & 0.720666567 \\
\hline$\pi \mathrm{e}$ & 0.23836799 & 0.18230171 & 0.077232037 & $\pi 1 \mathrm{e}$ & 0.231321944 & 0.230477476 & 0.195283758 \\
\hline$\pi 2 \mathrm{e}$ & 0.131561696 & 0.049652592 & 0.007845428 & $\pi 2 \mathrm{e}$ & 0.140397638 & 0.096177458 & 0.058699093 \\
\hline$\pi 3 \mathrm{e}$ & 0.072728882 & 0.013572051 & 0.000804775 & $\pi 3 \mathrm{e}$ & 0.085338438 & 0.040227667 & 0.017703152 \\
\hline $\mathrm{P}(\mathrm{S}>17)$ & 0.089919589 & 0.005106585 & $9.21 \mathrm{E}-05$ & $\mathrm{P}(\mathrm{S}>17)$ & 0.132291665 & 0.028930367 & 0.00764743 \\
\hline Norm & $7.28 \mathrm{E}-05$ & $8.04 \mathrm{E}-08$ & $8.34 \mathrm{E}-13$ & Norm & $1.46 \mathrm{E}-04$ & $5.64 \mathrm{E}-06$ & $2.02 \mathrm{E}-07$ \\
\hline Arrival Rate & 1.3875 & 1.0375 & 0.6875 & Arrival Rate & 1.7375 & 1.7375 \\
\hline Service rate & 1.775 & 1.775 & 1.775 & Service rate & 2.1375 & 2.7375 \\
\hline $\mathrm{E}(\mathrm{S})$ & 6.02049451 & 2.375371055 & 1.069637593 & $\mathrm{E}(\mathrm{S})$ & 7.305500432 & 3.871771634 & 2.631698215 \\
\hline Variance $(\mathrm{S})$ & 45.25702272 & 9.215029858 & 2.772200549 & Variance $(\mathrm{S})$ & 64.28060484 & 20.77694788 & 10.85512971 \\
\hline
\end{tabular}
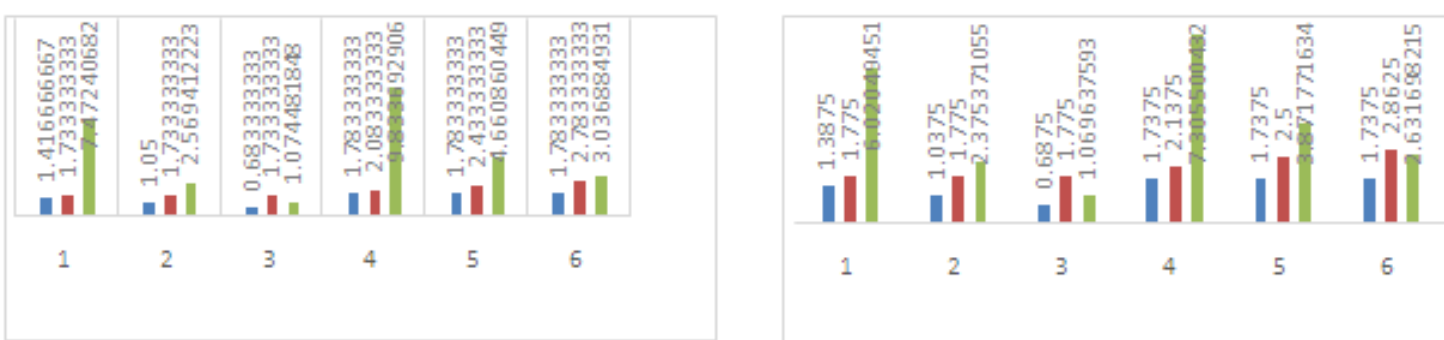

Figure 1 Model (A) Arrival, Service rates and E(S) Figure 2. Model (B) Arrival, Service rates and E(S)
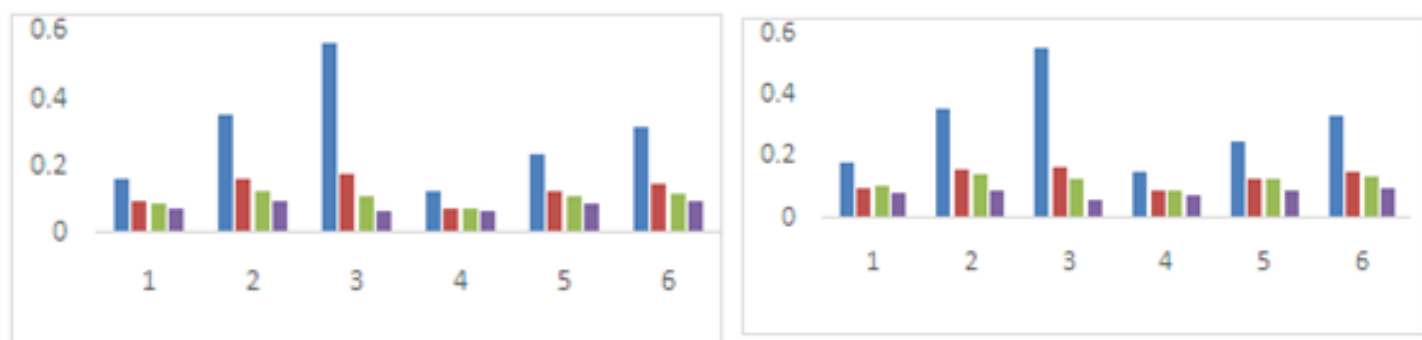

Figure 3. Model (A) $\mathbf{P}(\mathrm{S}=\mathrm{i}), \mathrm{i}=1,2, \quad$ Figure 4. $\operatorname{Model}(\mathrm{B}) \mathrm{P}(\mathrm{S}=\mathrm{i}), \mathrm{i}=1,2$, 


\section{Conclusion}

Two M/M/1 bulk arrival and bulk service queues with randomly varying environments have been treated. The environment changes the arrival rates, the service rates, and the probabilities of sizes of bulk arrivals and bulk services. Matrix geometric results have been obtained by suitably partitioning the infinitesimal generator by grouping of customers and environments together. The basic system generators of the queues are block circulant matrices which are explicitly presenting the stability condition in standard forms. With the same method of grouping of the customers, $\mathrm{M} / \mathrm{PH} / 1$ and $\mathrm{PH} / \mathrm{M} / 1$ queues with both bulk arrivals and bulk services have also been treated as special cases. Numerical results for varying bulk queue models are presented and discussed. Effects of variation of rates on expected queue length and on probabilities of queue lengths are exhibited. The decrease in arrival rates (so also increase in service rates) makes the convergence of $\mathrm{R}$ matrix faster which can be seen in the decrease of norm values. The variances also decrease. Bulk PH/PH/1 queue with randomly varying environments causing changes in sizes of the $\mathrm{PH}$ phases may produce further results if studied since $\mathrm{PH} / \mathrm{PH} / 1$ queue is a most general form almost equivalent to $\mathrm{G} / \mathrm{G} / 1$ queue.

\section{References}

[1]. Aissani.A. and Artalejo.J.R. 1998. On the single server retrial queue subject to break downs, Que. Sys.30, 309-321.

[2]. Ayyappan.G, Muthu Ganapathy Subramanian. A and Gopal Sekar. 2010. M/M/1 retrial queueing system with loss and feedback under pre-emptive priority service, IJCA, 2, N0.6,-27-34

[3]. D. Bini, G. Latouche, and B. Meini. 2005. Numerical methods for structured Markov chains, Oxford Univ. Press, Oxford

[4]. Chakravarthy.S.R and Neuts. M.F.2014. Analysis of a multi-server queueing model with MAP arrivals of customers, SMPT, Vol 43, 79-95,

[5]. Gaver, D., Jacobs, P., Latouche, G, 1984. Finite birth-and-death models in randomly changing environments. AAP.16,715-731

[6]. Latouche.G, and Ramaswami.V, (1998). Introduction to Matrix Analytic Methods in Stochastic Modeling, SIAM. Philadelphia.

[7]. Neuts.M.F.1981.Matrix-Geometric Solutions in Stochastic Models: An algorithmic Approach, The Johns Hopkins Press, Baltimore

[8]. Neuts. M.F and Nadarajan.R, 1982. A multi-server queue with thresholds for the acceptance of customers into service, Operations Research, Vol.30, No.5, 948-960.

[9]. Noam Paz, and Uri Yechali, 2014 An M/M/1 queue in random environment with disaster, Asia- Pacific Journal of OperationalResearch01/2014;31(30.DOI:101142/S02175959 1450016X

[10]. William J. Stewart, The matrix geometric/analytic methods for structured Markov Chains,N.C State Universitywww.sti.uniurb/events/sfmo7pe/slides/Stewart-2pdf. 